\title{
Bodies, Movements and Desires: Lesbian/Gay Subjectivity and the Stereotype
}

\section{Rob Cover}

Gay and lesbian discourse has a markedly complex relationship with the contemporary understanding of stereotypes as symbolic and connotative codes fixing an image to a set of prescribed behaviours. In its political and advocacy modes it frequently denounces the stereotyping of lesbians and gay men, arguing that stereotyping is a reduction of unique individuality and diversity into wrongful notions of group behaviour. According to Richard Dyer, a stereotype is taken to express a general agreement about a social group, as if that agreement arose before, and independently of the stereotype' (Dyer, 1993, p. 16). At the same time, however, lesbian/gay discourse articulates a need for group visibility, as expressed in lesbian/gay protest marches and the more celebratory Pride Parades in cities across Europe, North America, Australia, New Zealand and other 'Western' regions. Although such visibility drives are often linked with a local political issue, they are necessarily reliant on the presentation of a visually unified group of people through recognizable stereotyping by fixing a visible bodily image to a set of ideas, attributes, behaviours or dispositions; a shared sense of identity corresponsive with the promotion of belonging. While costuming, performance-of the conscious, voluntary and theatrical kind-and gender-play are often the mode through which this visibility is communicated, such visible presentations can be said to signify lesbian/gay group imagery and prescribe behaviours on to the bodies of other lesbian and gay identifying individuals.

At stake, here, is the issue of what I will call lesbian/gay self-stereotyping. By this I mean two things. Firstly, the lesbian/gay cultural production of a small range of fixed categories of visually recognizable lesbian and gay bodies-effeminate youthful males, the muscular 'clone', the groomed, toned male, and butch and femme lesbians, are just a few examples. All of these employ various plays on femininity and masculinity and many are, in some way, 'positively' oppositional to various mainstream stereotyping of lesbian/gay subjects such as the older yet circulating stereo-

Rob Cover teaches media studies and new media at Victoria University of Wellington. His research interests include queer theory, media reception and identity performativity and the emerging field of electronic gaming. Correspondence to: Rob.Cover@vuw.ac.nz 
types 'sad young man' (Dyer, 1993, p. 42) or the 'aggressive lesbian'. There is, of course, a notable and marked shift from the stereotype of the camp and effeminate homosexual male epitomised in 1970s representations as Mr Humphries in Are You Being Served to a more chic, groomed, and marketable figure we see represented in, say, models for Calvin Klein or Abercrombie and Fitch. However, the core of a 'disturbance' in culturally given norms of gender performance continues across these changing characterizations. These also differ from the range of stereotypes of 'the bisexual' which often do not perform a play on gender, and are stereotyped around issues of undecidability, rampant sexual needs/desires, lying, cheating and experimentation (Bryant, 1997).

Secondly, what might appear the voluntarist adoption of the codes of those stereotypes can, in a queer theoretical post-structuralist position, be understood instead as implicated in maintaining the myth of fixed subjectivities. Following Judith Butler's (1990, 1993) work on gender performativity, lesbian and gay subjectivities are considered in queer theory to be performed 'in accord' with discourses through the repetitive citation of a given norm, retroactively producing the illusion that the subject is fixed, with a stable inner core. This process can be said to include the re-constitution of subjects as sexual subjects after access to discourses of sexuality at legitimated post-pubescent ages, as well as the materialization of a sexual body constituted in and by discourse though never wholly determined by discourse. If stereotypes indicate a fixity of knowledge about apparently visible groups of bodies and their subsequent actions or 'what they are like' (Dyer, 1993, p. 87), yet are circulated and deployed discursively as tactics of racism, sexism and homophobia (Cranny-Francis, 1995, p. 50), then they are implicated in the materialization of lesbian and gay bodies (Butler, 1993, pp. 4, 15), and what Alphonso Lingis understands as the body's 'capacities, skills and inclinations' (Lingis, 1994, p. 53), which might be said to include the bodily performance of a sexual subjectivity. Where stereotypes are a specific kind of linguistic formation which fixes ideas about the abilities, inclination and attributes of bodies-that is, their behaviour, desires and articulations - there are significant issues at stake in the ways by which the stereotype governs discourses cited by performative subjects, and the ways in which these subjects are constituted, regimented, disciplined and normalized. This becomes a particularly pointed issue in an increasingly media-saturated culture in which discourses are predominantly disseminated within a mediasphere reliant on stereotypes for the quick and easy communication of ideas.

In this paper, I analyse the link between the lesbian/gay visual stereotype, the performativity of the embodied sexual subject in accord with available discourses, and the ways in which these effect and are effected by contemporary notions of subjective fixity. Taking a queer theoretical position, I first examine some recent work on stereotypes by Mireille Rosello in order to show how even a liberal stance on positive stereotyping has regimentary and disciplinary effects, and contend with some of the contemporary identifiable lesbian/gay stereotypes. This is followed by a discussion on the ways in which stereotyping of bodies is part of a discursive regime of enacting subjectivities. I then go on to show how the visual stereotype can be 
linked with constructions of the fixed lesbian/gay body and 'behaviour' in terms of bodily movement and the production of bodily desire before applying these points to two specific case studies: a magazine advertisement, and the claim by North American fundamentalist Christian leader Jerry Falwell that a fictional children's television character is gay. The concern here is to provide various ways in which to understand how mass-circulated, reductive media images of lesbians and gay men provide, in a tiny 'byte', a great deal of information on what constitutes the intelligibility and coherence as necessary for the successful performance of a lesbian or gay sexual identity. While neither wholesale nor impelled, and aside from discussions of 'passing', diversity, 'straight acting' lesbian/gay people, what might be asked in light of the rejection of essentialist understandings of sexuality is how particular looks, behaviours, patterns of voice, movement, stance, pose and, indeed, desire are replicated over recent time.

\section{What Use the Queer Stereotype?}

A stereotype, as Mireille Rosello has pointed out, transmits ideas, images, and concepts, but it does so by freezing a certain stage of the production of the text' (Rosello, 1998, p. 23). The widespread understanding of stereotypes in liberal-humanist and lesbian/gay discourses is that they transmit a fixed un-truth about a group of people. For example, Sarah Schulman blames the mass proliferation and circulation of particular images of gay men in glossy magazines for the false representation of gay people; she suggests that there is a 'Fake, Public Homosexual' (Schulman, 1995, p. 13). Similarly, Richard Dyer claims that stereotypes operate to 'make fast, firm and separate what is in reality fluid' (Dyer, 1993, p. 16). Michèle Barrett points to a number of texts dealing with stereotypical representations which suggest that such representations are 'distortions ... of reality' (Barrett, 1988, p. 91). These accounts portray stereotypes as either textual or image representations which effectively convey a false and reductive knowledge about groups of people. However, they uphold the notion that there is therefore some 'truth' or 'reality' that is obscured by the circulation of stereotype.

In her Declining the Stereotype, Rosello questions the political efficacy of opposing stereotypes on the grounds of a cultural truth, pointing out that like the printers' tool from which the term is derived, stereotypes are used to 'fix' images to ideas, and prevail through their iterativity and mass circulation (Rosello, 1998, p. 24). She goes on to suggest that any citation of the stereotype in order to denounce it effectively puts it into further circulation (Rosello, 1998, p. 29). She asserts that 'stereotypes always imply a theory of identity' (Rosello, 1998, p. 15) and that if stereotypes are a branch of the art of representation they have to be treated 'not as the opposite of truth but as one of the narratives that a given power wants to impose as the truth at a given moment' (Rosello, 1998, p. 17). For Rosello, varying stereotypes occurs in much the same way a word is 'declined' grammatically where prefixes and suffixes vary the meaning, but the root or core term remains central. To address stereotypes, therefore, is to change their implications while accepting that a core linking of an 
image to an idea remains for a much longer period. Hence the political answer to stereotyping and its deployment for the disempowerment of particular groups is to refuse to intervene through opposition, for that will cite and therefore further circulate the stereotype (Rosello, 1998, p. 19). Instead, it is to make use of techniques of declension to 'recycle' the valence of stereotype into 'a relatively harmless event' through both reappropriation and a process of declining (in both the linguistic and rejection sense jointly) the meaning behind the stereotype (Rosello, 1998, pp. 20, 40).

While this appears a useful linguistic tactic, what Rosello ignores is the way a stereotype, whether harmful and negative or harmless and positive, will reduce a set of ideas into an easily communicated and culturally intelligible image, stemming the flow of signification and constraining the possibilities for diverse subjective performances. This occurs through the coterminous parallel between image to idea and body to action (or body to attributes, body to behaviour, body to desire), whereby a given, identifiable, recognizable body is expected to behave in particular ways, much as a stereotypical visual image is expected to provide particular ideas. As a source for the performance of identities, stereotypes operate through pervasiveness and iterativity of their images, and can be thought of as an element of what Chantal Mouffe refers to as 'nodal points'-linguistic functions which prevent the slippage of signifieds under the signifier (Mouffe, 1995, p. 34).

Although I would like to embrace Rosello's point about the danger of denouncing stereotypes through citing and thus re-circulating them (Rosello, 1998, p. 19), I will nevertheless make reference to a handful of perceivable stereotypes of lesbians and gay men in order to show the range and complexity of these stereotypes and the 'core' citation that inhabits that range. Stereotypes circulating in both 'the mainstream' and in lesbian/gay media culture, such as the lesbian/gay print press, are representations (imaged, vocal) of bodies linked with concepts of behaviour or motion. Predominantly it is the image-body parallel which is significant for its representation. The dominant form of the visual-stereotypical representation in lesbian/gay culture is through the medium of photography, which proliferates in lesbian/gay print publications, pornographic magazines, AIDS-related health warnings, glossy magazine advertising and pictorials. Lesbian/gay stereotypes are recognizable in that they are circulated widely and repetitively such that they can easily be read from a common cultural discursive 'reading formation', to use Tony Bennett's term (Bennett, 1983, p. 216).

Schulman's accusation against the circulation of a 'fake' homosexual image in national gay magazines suggests that they depict or connote narrowly commodified notions of homosexual life and of an openly gay consumer. She claims that the majority of gay and lesbian people have little or no representation of their lives in the media and are 'instead bombarded by the A-list, white, buff, male, wealthy stereotype that becomes the image ... of the average gay person'. At the same time, she suggests, there is no 'standard preferable body type' of lesbians at all, implying that invisibilization of lesbians results in no lesbian stereotypes at all (Schulman, 1995, p. 13). However, Barbara Creed identifies several stereotypes of the lesbian in 
mass-circulation films 'which draw so heavily on the visual' ranging from mannish imposter, fanged vampire, prim professor, frustrated nun, and man-eating monster (Creed, 1995, p. 87).

Although it is a common perception of lesbian/gay people that they are in some way not conforming to gender performances (Whisman, 1996, p. 124), such nonconformity to heteronormative gender operates as the core element which underlies the variances within the range of stereotypes that are both possible and circulated. The well-groomed male (where careful and concerned grooming is connoted as a feature of femininity) and the mannish or vampirous woman (where wearing trousers or having short hair is considered a feature of masculinity) are both stereotypical images dependent on certain re-figurations of gender. This is not, of course, to suggest that these in any way permit the resignification of gender norms in general, for the relegation of this play to 'lesbian' and 'gay' serves to uphold dyadic masculine/feminine gender norms. Operating similarly is the hypermasculine stereotype 'clone' North American gay male of the 1970s. The hypermasculine has often been read as a figure of domination and heroism (Mohr, 1992, pp. 163-164). A play, however, occurs not just in the extension of masculinity well beyond what might be deemed 'fit' or 'toned', but in the play between over-masculinization juxtaposed with same-sex desire; testosterone-driven sexuality juxtaposed with passive sexual submission. Gender play does not necessarily question or destabilize gender norms as long as it is framed-off, as it were, by the name homosexuality. Instead, this play underlies the stereotypes of homosexual subjectivity by linking in gender non-conformist behaviour, such as desiring the 'wrong' way, with a gendered body. As a result of such stereotyping, the image of an effeminate 'straight' male is often misunderstood to perform non-masculine actions, movements and desires; at the same time, anyone operating a sexual subjectivity under the name 'gay', for example, is thus presumed to have an appearance (image; body) that varies 'normal' gender codes, even if only slightly. This provides what I suggest is the core of the recognizable cultural stereotype in the West. Such (regimented) gender play is part of a stereotype extending back at least a century, and publicized significantly through the trial of Oscar Wilde (Sinfield, 1994). According to Foucault:

In nineteenth-century texts there is a stereotypical portrait of the homosexual or invert: not only his mannerisms, his bearing, the way he gets dolled up, his coquetry, but also his facial expressions, his anatomy, the feminine morphology of his whole body, are regularly included in this disparaging description. The image alludes both to the theme of role reversal and to the principle of a natural stigma attached to this offense against nature. (Foucault, 1985, p. 18)

The evidence that a play with gender has continued to constitute the core lesbian/gay stereotypes, despite the relatively recent disdain for the notion that homosexuality is indicative of a gender 'offence against nature', suggests that Rosello's understanding of the declension of stereotypes operates similarly in the case of lesbian/gay stereotyping. The root of the stereotype is the evidence of gender play in the imaged depiction, but the form of the play varies considerably. Where Creed advises that one 
popular lesbian stereotype is the 'masculinized body' (Creed, 1995, p. 88), I suggest that this is in fact the core of stereotypical variants on the lesbian image. Schulman's point that there is no lesbian stereotype, then, is not due by any means to an invisibility but perhaps results from a greater range of types which cannot so easily be reduced to one representative body, obscuring the masculinized core.

\section{Lesbian/Gay Performativity and Visuality}

The performativity of sexual subjectivity, in Butler's analysis, requires the citation of the signifier or the 'proper name', performed reiteratively and stabilizing over time. In a culture heavily governed by an imperative that one be an intelligible, legitimate and coherent subject-and a sexual subject-we are impelled to constitute our sexual subjectivity as either hetero or homo. That which is external to the pervasive hetero/homo binary is frequently considered illegitimate and incoherent, so for the vast majority sexual performativity involves the citation of the names hetero or homo, gay or straight. ${ }^{1}$ The cited proper name 'homosexual', however, need not be spoken as such. In Excitable Speech Butler claims

the words, 'I am homosexual,' do not merely describe; they are figured as performing what they describe, not only in the sense that they constitute the speaker as a homosexual, but that they constitute the speech as homosexual conduct. (Butler, 1997, p. 107)

It is not only words that perform what they describe-image-presentation itself acts in the same way as those words; the presentation of a body in terms of homosexual codes and connotations is similarly 'homosexual conduct'. In other words, the visual codes of culturally intelligible lesbian or gay performativity can be an element of the reiterative performativity of an illusive subjectivity.

Visual codes accomplish more than the discursive reinforcement of a group or collective or representative set of identities. There is a practical purpose: a person who understands her or his lesbian/gay subjectivity as an attraction to a particular gender (what is perceived or understood as the same gender as that person's own subjective gender or bodily sex as performed in accord with culturally given gender codes) will likely wish to act on that understanding by seeking an object(ive)—coupling with a partner or seeking a sexual encounter or other ritualistic behaviour. In order to display that endeavour in spaces which continue to be overtly heteronormative, it is necessary to adopt visual markers in appearance. At the same time, visibility and visual markers are sometimes a necessary response to the often-heard heteronormative reaction to an announcement of non-heterosexuality: why are you 'in such a hurry to jump to conclusions?' (Sedgwick, 1990, p. 79). Mariam Fraser suggests that this comment is often made owing to the lack of 'visual proof' of homosexuality (Fraser, 1999, p. 110). One might suggest, then, that visual proof becomes a necessary and expected element in the performativity and subjectification of nonheterosexuality as homosexual performance. As Butler has remarked, identity categories 'depend upon appearance for their social legibility' (Butler, 2000, p. 59). 
Subjective performativity is the citation of discursive norms, but such a citation may sometimes require the adoption of visual norms in order to fulfil the contemporary cultural imperative of coherent identity. At the same time, the visuality of the stereotype is further circulated and reinforced as a requirement of various visual media forms. Recent gay-affirmative mass-circulation films such as In and Out (1997) and The Opposite of Sex (1998) rely on visual, recognizable stereotypes to communicate a great deal of information in a short, visual 'byte', effectively providing reductive character detail in an image (Cover, 2000). The requirements of narrative flow in television depend even more markedly on the speed and encapsulation of stereotypic data about a character represented visually-particularly in recent television such as Will and Grace, the US rendition of Queer as Folk and perhaps most notably in the Bravo reality television show Queer Eye for the Straight Guy with its strong emphasis on grooming and clothing. Even as recent television and film seeks to disavow or reject a stereotype in the longer play of its narrative, it is-as Rosello has suggested-often an act which continues the circulation of the stereotype-no theory of audience would now suggest that all viewers activate a reading which rejects the stereotype in any universal way.

Stereotypes are identifiable because they are disavowed. There are subjective performances which are in a relation of indifference to the stereotype. As Butler has asked: 'How do we account for the transformation of the stereotype within the practice of gender if there were not something else in gender, as it were, that is not immediately co-opted or foreclosed by the stereotype' (Butler, 2000, p. 60). It is in view of this question that I want to suggest that subjective performances can be seen to be governed by the stereotype's linkage of body, image, attribute and action, but that this in no way terminates the possibilities of performances of that subjectivity outside of the cultural rules of the stereotype. Rather, in fulfilling both the imperative of coherent sexual subjectivity and the practical needs of sexual minority community ritual and contact, the citation of the stereotype is the more intelligible process - thus enabling the recognizable coherent performativity of a sexual body and its sexual actions.

These self-stereotypical codes may include subjective performativity of the body through particular stances, gestures, vocal intonations, glances, gazes, and looks. The body, however, does not stop at the skin. Hair, clothing, grooming, accessories and self-presentation are as much elements of the body as are organs, skin, nerves, muscles, flesh. Although Harvey and Shalom claim that in lesbian/gay communities there is a system of masquerade, consciously adopted identities signified through 'systems of fashion, accessories and language' (Harvey \& Shalom, 1997, pp. 13-14), I am not convinced that the adoption of such codes need necessarily be only a conscious and voluntary theatrical act. While it is the case that twentieth-century homosexual culture contains a dynamic of what Cindy Patton calls 'survival tactics' of 'performing' and 'unperforming' (signifying and passing), usually by the subversion or hyperperformance of gender signifiers (Patton, 1993, p. 87), it would be a fallacy to imagine a fixed body on which hangs various stereotypical adornments. As Lingis writes: 
We conceive of our person as a subsistent constant, perceivable in the stable shapes and contours of our bodies, the recurrent verbal and behavioral patterns of our initiatives, and the recurrent diagrams of our emotions, attitudes, and posturings. It would be perceivable too in the consistent ways in which we clothe and adorn our bodies and in the stable social roles and functions in which we insert ourselves. (Lingis, 1994, p. 155, emphasis added)

No less inscriptive than muscular exertion, says Elizabeth Grosz, is the "habitual marking of the body by clothing, ornamentation, prosthetic devices, and makeup' (Grosz, 1994, p. 144). Because, in a post-structuralist analysis, there is no subject behind the performative act of choosing such clothing and adornments, it can be said that these elements of the bodily performance-in line with the cultural stereotypes-are just as much an aspect of the performativity of a sexual subjectivity as the expression of desire for, in a lesbian/gay subjective performance, a 'same sex' body.

\section{The Intelligibility of Sexuality and the Body}

Reiterative performance of a lesbian/gay sexuality serves to provide not only the illusion of an inner core but also to convince those subjects that mythical subjectivity is totalized - that a particular sexual subjectivity permeates and directs bodies, behaviours and desires; the 'body and soul', as it were. It is through the very reductiveness of the stereotypes that such totalization becomes possible. The stereotype, as Dyer suggests, presents an image, particularly in film, in which the 'fact of a character's gayness [remains] clearly present before us through the text. This has the disadvantage that it tends to reduce everything about that character to his/her sexuality' (Dyer, 1993, p. 23). The totalization of a subjectivity, the constitution of the 'I' as a 'gay I' or 'lesbian I', is only possible through the materialization of a subject as having a gay body and a gay soul, noting that the Cartesian mind/body dyad is certainly in force in contemporary Western humanist thinking. If performativity is the reiteration of norms or a set of norms (Butler, 1993, p. 12), and if performativity creates the illusion of a subject's core identity, then it is not just through visual-stereotyping that the norms are circulated for this reiterative performance, but it is through the presentation of a body as a gay or lesbian body that can locate this reiterative performativity. The contemporary conception of the body as whole, unified, natural, and fixed is a linear conception. According to Lingis, we perceive our bodies as 'constant' and 'stable' (Lingis, 1994, p. 155). If subjectivity is dependent on reiterative performativity, then a linear performance of the 'static' body is constant and disguises the fact of reiterative performance. In other words, it is not that reiterative performativity is a series of independent 'acts' as such, but that in the perceived linear and stable conception of the body it is an ongoing reiteration in continuity and stable, fixed subjectivity. This is not to suggest that there is no possibility of undermining subjectivity-in pointing out the necessity of repetitive citation, Butler makes clear the ultimate impossibility of consolidation of the dissociated unity of the subject (Butler, 1997b, p. 93). The linear constancy of the 
body is mythical, an illusion that is itself dependent on repetitive performativity for its very materialization as constant.

But what is a gay or lesbian body? Lesbian/gay culture provides a range of essentialist and constructivist possibilities in attempting to locate sexuality, the most popular being the assertion of a gay gene, suggesting that sexuality is wholly a bodily affair. ${ }^{2}$ In contemporary (and scientific) discourse, it is sometimes suggested that particular genes (in their location in the body) cause particular sets of expected behaviour or inclinations. In this case, it is the search for a mythical gene that causes a lesbian/gay sexuality and thus lesbian/gay behaviour. Such notions, however, rely on the idea of the body as an a priori given: foundational, material and self-contained. In queer theory fashion, I reject the view that a body is to be seen as 'real' and 'material' in opposition to cultural and historical representations of the body, but understand the body to be constituted and produced by such representations. For Grosz, the 'body' is a concrete and animate organization of flesh given unity, cohesiveness and form through psychical and social inscription on the body's surface (Grosz, 1995, p. 104). While Grosz operates from a psychoanalytic perspective in this definition, the psychical map of the body that in a Lacanian conception originates at the point of the mirror-stage (Lacan, 1977, p. 19) is not unassimilable to the Foucauldian discourses of disciplinary inscription on 'docile bodies' (Foucault, 1977, p. 138). Like Butler, I suggest that bodies themselves are 'materialised' in that inscription (Butler, 1993, pp. 4, 15) and are only understood as whole, unified and naturalistic through that inscription or subjection. The psychical map which is said to precede the body can in some respects be seen as the Foucauldian 'soul', particularly if we take Butler's account in which she suggests it is a 'kind of psychic identity' that imprisons the body through inscription (Butler, 1997b, p. 85). While there is a conceptual difference between a Freudian/Lacanian psyche and a Foucauldian soul, the assimilation works adequately to use the Grosz definition of the body while locating the psyche as the effect of discursive subjection.

The body is a productive necessity for subjectivity: there is no lesbian/gay subject that is disembodied as such. The subject must, as Grosz puts it, 'be able to situate himself as a being located in the space occupied by his body' (Grosz, 1995, p. 89). This is a condition of coherent identity. As the most efficacious means by which media discourses can circulate 'knowledges' about bodies and people, the stereotype will frequently-although by no means exclusively—operate as the discursive model for this lesbian or gay body.

\section{Stereotypical Imagery and the Movement of the Body}

I will now move from looking at the lesbian or gay body in terms of the visuality of the stereotype and consider the ways in which stereotyping governs 'what a body does'. By 'doing', I mean the movements, spatial relations and gestures of the body-that which is commonsensically understood to extend from the body, but which from a performativity viewpoint reiteratively constitutes 'being'. In other words, I do not mean that a body has been previously produced and then goes on 
to act or move or desire (a bodily doer behind its deeds), but that in its movements the body is constituted as a specific type of body. At the same time, a dynamic operates through the cultural force of stereotyping to suggest a sensibility in which a particular imaged body will make movements in particular ways. This is in line with the knowledge element of the stereotype, whereby the stereotype employs a visual image and the cultural connotative knowledge provides it with attributes. In her analysis of the physical capabilities of women, Iris Marion Young (1990) makes a connection between the subjection of women as women and the ability of a womanly body to perform within a certain range of actions, such as particular ways of throwing a ball. Although Young operates with a modified phenomenological account of bodies and provides the body with an originary materiality (Young, 1990, p. 146) which I refuse here to take as given, she shows that it is in the discourses of feminine bodily comportment that the womanly body may be unable to, for example, 'summon the full possibilities of our muscular coordination, position, poise, and bearing' (Young, 1990, p. 145). She will throw 'like a girl', as it were, rather than as a man. One might speculate here that this account is rather dated and that a survey of women in, say, recent film would suggest that there is a move towards depictions of bodily athleticism. Nevertheless, Young's argument works well to describe the ways in which subjection under specific labels makes possible certain bodily movements as, in Lingis' phrase, 'capacities, skills and inclinations'. The assignation of identities to the bodies of others, as Lingis suggests, has the power to pain or gratify subjects (Lingis, 1994, p. ix). I suggest that these sorts of identities to which Lingis refers can be labelled stereotypes in terms of their role as the culturally intelligible-if reductive-codes of particular subjectivities. This is particularly so in the ways in which a stereotype operates to make that link between the imaged-body and the movement (capacities, skills, inclinations) of the body. Such stereotyping may pain or gratify, which although seemingly reductive does imply that a subject may view stereotypes retrospectively as either positive or negative. The connection between image and body movement is likewise seen in the work of Grosz, who suggests that the 'body image includes both the representation of the movements necessary to attain a specific goal and all the various intermediary actions required to move the body from its present position to this goal' (Grosz, 1994, p. 69).

Performativity of the body-movement 'in accord' with the image-idea construct of the stereotype is a means by which to constitute and regiment the sexual subject. For Foucault, it is discourse which enacts 'an infinitesimal power over the body', coercing specific 'movements, gestures, attitudes and rapidity' (Foucault, 1977, pp. 136-137). This disciplining of the body-in light of the 'exercising' analogy which disciplining invokes-is for the production of 'docile' bodies (Foucault, 1977, p. 138). I differ from Foucault's point by rejecting the givenness of the body as tabula rasa on which discourse acts, and suggest instead that it is through a more complex application of discursive formations in which the body is made not just docile or submissive to act in particular ways in accord with a particular subjectivity, but is also materialized as a coherent body through the force of a discursive formation operating performatively. 'Hailed' to a discourse under the rubric of the cultural 
imperative to be a coherent sexual subject, the illusional subject must go on to stabilize his or her subjectivity by the presentation not only of a sexually subjected body but through the reiterative performativity of the movements of the body-capabilities, attributes, lifestyles (Butler, 1993, p.9). For such performance to be effective-that is, to fulfil the cultural imperative of coherence-it must be culturally recognizable, which is in addition to, and aside from, the practical purposes of recognizability in order to engage or indicate sexual or emotional interest along same-sex trajectories.

In the case of lesbian or gay subjectification, it is the codes represented by the stereotype as linking image to attribute (the formulation image-idea) which discursively enacts the body and its movement regime (formulated as body-movement). The sorts of movements (capabilities, skills, inclinations) that are possible by the imaged lesbian or gay body serve to subjugate that body and materialize it as a coherent (gay or lesbian) body through the application of discourses reliant on the stereotype's linking of image and attribute. This complex formulation is, in fact, most clearly betrayed by contemporary notions which understand a lesbian/gay subject to have a doer behind its deeds; a static lesbian/gay body (being) and a lesbian/gay doing.

I will take an absurd example: in early 1999, North American Christian right-wing leader Jerry Falwell accused the children's television character Tinky Winky of the Teletubbies of being 'gay'. In the February 1999 edition of his publication National Liberty Journal, he claimed that Tinky Winky has the 'voice' of a boy but 'inappropriately' carries a purse-like magic bag. Further, Tinky Winky 'is purple-the gay-pride color; and his antenna is shaped like a triangle-the gay-pride symbol' (Reed, 1999). Falwell's belief is that these are specific gay innuendos. He complained that as 'a Christian I feel that role modeling the gay lifestyle is damaging to the moral lives of children'. Falwell's reading of Tinky Winky's gender as male-based on voice-is at odds with my own reading. I suggest that what is interesting about the Teletubbies characters is that they are among the first to be marketed to children as gender-less characters, with the notable exception of the androgynous Sesame Street character Big Bird. Such genderlessness, of course, risks their being read as male where male remains the cultural template of the body (Irigaray, 1985, p. 69).

This amusing case of religious paranoia-gone-rampant shows the dynamic of the image-behaviour of the stereotype. Tinky Winky is identified or recognized as 'gay' because of a certain gender play in the depiction of his or her sexed attributes, an identifiable masculinity yet the grooming and accessorizing (the handbag and whatever it might contain). Performance of the signifiers of lesbian/gay culture such as the wearing of culturally recognizable symbols — the triangle-in Falwell's reading confirm his suspicions, but the identification is made not by the symbols but through application of the stereotype. Falwell sees the image of a 'gay body', and in accord with the stereotype presumes that Tinky Winky has the capacity for particular types of movement (gay behaviour or 'lifestyle') and particular types of desire (same sex). For Falwell, Tinky Winky clearly has a gay body (the triangle, even, is firmly attached to the character's head as a body part), as much as Falwell's philosophic 
position rejects any notion of a 'natural' embodied sexuality other than the heteronormative. It is only through the stereotype's iterative governance of cultural knowledge of sexuality that Falwell is able to make the inference that Tinky Winky's body moves in particular ways; that is, desires along same-sex trajectories. Sesame Street's Cookie Monster, with his chronic eating disorder, does not come under Falwell's scrutiny, perhaps because Falwell is yet to make a link between sexuality and eating disorders, or more likely because his gruff voice, ragged costuming and aggressive behaviour signify for Falwell a stable modernist masculinity. No one is asking what it is precisely that Cookie Monster does or desires, because his body does not come under the culturally accessible knowledge regime of a gay stereotype.

\section{The Stereotype and the Trajectory of Desire}

I am expanding the notion of body-image trajecting towards a regulated body movement through the cultural stereotype by elaborating 'movement' to incorporate not just cultural understandings of spatial (dis)location, stance, gesture, capability, capacity, activity or attribute but also desire. A feminine subject might, in Young's words, throw like a girl in accord with her subjection and bodily materialization, but she might also desire like a girl for the same reasons (i.e. desire along hetero or homo lines). In contemporary cultural discourses, one might ask what does a lesbian body do? It desires a woman. Among other stereotypical performances, it desires a woman. If gay/lesbian desire is pleasurable when it is (presumably, potentially) fulfilled through sexual performance or emotional coupling, then the appeal of stereotypical 'movement' (as desire) can be understood. Such regulation operating between the imaged body and the performatively produced movement of desire (regulated as directed towards one specific and coherent gender) is, in fact, a source of pleasure. It is the neutralization of the operations of the stereotype which links the materializing lesbian/gay subject-body to same-sex desire. This is what I am, and this is what I do, but in a dynamic reduced to an inseparability. The subjection of a body as a lesbian or gay body, thus, is a wiping out of the discursive operations of the stereotype through a compacting, as it were, of the myth of the essential gay body and its subsequent gay conduct. The performativity of such conduct creates the illusion of the essential core, and that core body is thereby seen to have specific, set trajectories of desire along gendered codes.

In other words, the signification of desire as gendered and its mythical trajectory from a lesbian/gay body-subject towards a specific gender (one perceived as the same as that of the subject) can be understood as the result of subjectification along the lines of the stereotype, whereby the performativity of the subject as 'lesbian' results in the question: what does a lesbian do? Well, she desires a woman. In this way, the movement from the categorized lesbian/gay body-subject to the trajectory of desire suggests that desire is the productive result of (stereotypical) subjective performativity in accord with discursive norms, whereby that discourse communicates what Foucault refers to as a 'moral code', rules for action, behaviour and conduct seen to 
stem from particular subjective selves (Foucault, 1985, p. 28). What this suggests is that the subject is not compelled to 'act' on desire by, for example, seeking out a coupling-partner or a sexual object of the appropriate gender. Instead, it is in the performativity of subjectivity as 'gay' or 'lesbian' and the performative effect of the discourse which encodes a normalizing process whereby the illusional subject is able to negotiate that performance, but only along or against coded lines of moral conduct such as the seeking of an appropriately gendered object as a gendered object. In this sense, then, it is not a matter of a coherent subject manifesting a trajectory of desire as either homosexual or heterosexual, nor is it solely about a performance of desire lending the illusion of a coherent subject. Rather, through a materialization of the body-subject (in process, in its performativity), and in terms of a discourse which relays the stereotype and its trajectory of body-movement/desire, a culturally intelligible code of subjectivity is made available.

Although Butler claims that the performative phrase 'I am homosexual' is often misconstrued as a solicitation, or the 'intention to act, or even the act itself (Butler, 1997a, p. 113), we might ask whether the same can be posited for the reverse. What happens when conduct is misconstrued as the emanation from a lesbian or gay body-subject? Through the operations of the stereotype dynamic, gay conduct is seen to betray a gay body (often supposedly hidden or 'closeted'). This is often the case with the lesbian/gay cultural fetish for 'outing' celebrities, usually on the basis of attempting to provide solid role-models in public media circulation (as if Walt Whitman and Ellen Degeneres were not enough). Outing is 'making publicly acknowledged the sexual orientation of a homosexual without regard to whether the person is willing to have this information publicly acknowledged' (Mohr, 1992, p. 11). Richard Mohr's assertion here is problematic in that it assumes a coherent 'homosexual' that pre-exists the public 'naming'. A stereotype must be in cultural circulation for such naming significations to be readable or recognizable or, for that matter, misrecognizable. Hence, when a celebrity is outed or named gay or lesbian based on gossip, rumour, innuendo or even on a verifiable action which can be perceived as homosexual but may not necessarily have been, it is because the act signifies diversely but as a result of the image-idea dynamic of the stereotype it is culturally signifiable as the act of 'a homosexual'. In other words, because of the discursive operation of the stereotype and its link between the subjective body and act or conduct, it is not the speaking-position of the naming speaker which authorizes but the cultural stereotype to which the name ('homosexual') must defer or ground itself upon for authorization.

Another example, but one which is neither atypical of the sorts of questions evoked by discourses on lesbian/gay stereotyping, nor startling to those with knowledge of the processes by which such questions emerge: in 1999 an advertisement for Ariston stoves featuring Angus Kennett, the popular son of a former Conservative Australian state premier, ran in a number of magazines, including Elle Cuisine, Australian Home Beautiful, Australian House \& Garden, Marie Claire, among several others. ${ }^{3}$ Print news media picked up on an article on the controversy produced by the photograph and its caption. According to a news article (Pristel, 
1999), the advertisement caused rumours to circulate that Angus Kennett is 'gay'. The advertisement's caption read:

I live with my best friend and we have a whippet called Clint. We like breakfast in bed, lazy Sundays and freshly cooked pizza. I'm taking a course in photography.

As Simon Pristel's article relates, the caption and the imagery of Angus Kennett being served pizza by 'a young man in a tight white T-shirt' marked Kennett as 'gay'. 'Best friend' has sometimes been used as a euphemism for a closeted same-sex relationship. Although neither the caption nor the photograph overtly suggests a male-male desire of either the characters or the models used, the 'movement' indicated in the caption make these implications possible in accord with the stereotype. 'Lazy Sundays', for example, circulates in lesbian/gay culture as a motif of same-sex domestic bliss (Ellenzweig, 1997, p. 67). Similarly, the shared pet and breakfast in bed could also have 'queer' meanings activated in their reading. The fact that this advertisement and its 'supplementary' caption was understood to mark or name Kennett as 'gay' suggests that the cultural stereotype dynamic linking a gay body-subject to gay conduct or gay desire operates in reverse from the formulation used above to discuss Tinky Winky's sexuality. The naming was possible only by the implications of conduct that circulate as cultural knowledge (what are people who have lazy Sundays, shared pets and breakfast in bed? Gay). In this sense, it is not just naming or perceived 'self-declaration' of homosexuality which can be understood to operate as homosexual conduct, but through the links initiated by the circulation of the stereotype, the perceived conduct comes to enact the naming.

This is not to suggest that the inferences made about the character's or the model's activities, desires and behaviours are either incorrect or should be seen as injurious. Rather, the question here is what occurs when a subject's acts or desires are recognized and identified in the terms of the stereotype. For example, a person whose desires are seen to be same-sex, that is, along the lines of the 'moral code' as Foucault has put it, may have nothing to do with their own experience of those desires. She or he may desire along trajectories that have nothing to do with gender, but along more imaginative and less constraining demarcations, as Eve Sedgwick (1990) has indicated in her critique of the gender basis of the hetero/homo binary. In this sense, then, it is the cultural intelligibility of the stereotype that accomplishes a dynamic between the materialization of a particular body (which comes to be named a 'gay body', for example) and the movements, desires and acts of a body which operate as reiterative performativity, thus providing the illusion of a foundational core. While on the one hand there is no given body-subject from which deeds project, neither is there a situation in which the deeds come to make the subjective body. Instead, there is a complexity of operations which subjectify and stabilize a notional body through intelligible performances. To put this another way, it is only by the materialization of particular bodies through the discursive organization of both flesh and actions that metaphysical thinking has been able to suggest the essentialist body in the first place, and that humanist thinking is able to retain the notion of the coherent body which acts. Rather than taking these views, a post-struc- 
turalist position permits us to see a dynamic between deeds which constitute the body and a body which is stereotypically trained in simultaneity to perform these deeds.

It must, however, be understood that where the cultural knowledge circulating in the stereotype permits naming, interpellation and thus the performativity of lesbian/ gay subjectivity, it is by no means necessarily determinant of all or any lesbian/gay articulations. While the stereotype is a discursive element cited in performativity, it does not foreclose on performances that are outside of the body-movement/desire dynamic - otherwise no such stereotype would be identifiable to be dismissed. The implications of this analysis in a queer theoretical perspective attempting to destabilize the regimentation of sexuality are directed not to the stereotypes but to the operations of language in the production, constitution and constraint of subjects. It is not, then, a matter of denouncing stereotypes - there is always present the danger of re-circulating them, as Rosello claims. Rather, disruption of the force of the stereotype can occur in the subjective reading of cultural knowledges of sexuality, and this is something that can usefully be promoted as a political tactic. What is necessary is to separate the image-ideas or body-movement/desire conflations of the stereotype by the equitable circulation of more marginal knowledges of sexuality which permit the performativity of an erotics outside the reduction of the hetero/ homo binary. Where the stereotype is the most effective communication of knowledges of non-heteronormative sexuality (what one is, what one does), then combating the stereotype is to compete with it and permit a contingent, proliferate range of representations to be circulated, disseminated and read.

\section{Notes}

[1] I will note here that we can be compelled to perform sexuality as bisexual, which while on the one hand it disrupts the hetero/homo binary by presenting a middle ground, on the other it reinforces the binary by its reduction of two 'positions' into one, thereby intensifying the positions. More importantly, bisexuality fortifies traditional codes of 'gender' as the primary object of sexual choice, in presenting the possibility of attraction to two genders (but no more), thus implicated in what Butler refers to as the heterosexual matrix (Butler, 1990, p. 12) which upholds significations of gender and sexuality. In that sense, I am unwilling to view bisexuality as illegitimate and incoherent, for it is firmly implicated within the 'authorized' dichotomy of sexual choices.

[2] It might be said that the biological essentialist myth of a bodily located root 'cause' of homosexuality is not altogether so recent an idea-Magnus Hirschfeld's late nineteenthcentury notion of a 'third sex' description of homosexuals is not dissimilar from the gay gene theory. Influenced by early sexologist Karl Heinrich Ulrichs, Hirschfeld believed that homosexuality could be determined by examining other physical attributes such as the size of the hips (Miller, 1995, p. 113). Interestingly, Hirschfeld believed that male homosexuals had wider hips than heterosexual men. This is contrary to the more recent stereotype which, as Michael Bronski points out, involves gay men having slimmer hips (Bronski, 1984, p. 170).

[3] The advertisement is featured on the Commercial Closet Website, which categorizes and archives ostensible and implicit lesbian/gay imagery in advertising (http:// www2.commercialcloset.org/cgi-bin/iowa/portrayals.html?record $=975$ ). 


\section{References}

Barrett, M. (1988) Women's Oppression Today: the Marxist/Feminist Encounter, revised edn, Verso, London.

Bennett, T. (1983) 'Texts, readers, reading formations', Literature and History, Vol. 9, no. 2, pp. 214-227.

Bronski, M. (1984) Culture Clash: the Making of Gay Sensibility, South End Press, Boston.

Bryant, W. M. (1997) Bisexual Characters in Film: From Anaïs to Zee, Harrington Park Press, Birmingham, NY.

Butler, J. (1990) Gender Trouble: Feminism and the Subversion of Identity, Routledge, London and New York.

Butler, J. (1993) Bodies that Matter: On the Discursive Limits of 'Sex', Routledge, London and New York.

Butler, J. (1997a) Excitable Speech: a Politics of the Performative, Routledge, London and New York.

Butler, J. (1997b) The Psychic Life of Power: Theories in Subjection, Stanford University Press, Stanford, CA.

Butler, J. (2000) 'Appearances aside', California Law Review, Vol. 88, no. 1, pp. 55-63.

Cover, R. (2000) 'First contact: queer theory, sexual identity, and “mainstream” film', International Journal of Gender and Sexuality, Vol. 5, no. 1, pp. 71-89.

Cranny-Francis, A. (1995) The Body in the Text, Melbourne University Press, Melbourne.

Creed, B. (1995) 'Lesbian bodies: tribades, tomboys and tarts', in Sexy Bodies: the Strange Carnalities of Feminism, eds E. Grosz \& E. Probyn, Routledge, London and New York, pp. 86-103.

Dyer, R. (1993) The Matter of Images: Essays on Representations, Routledge, London and New York.

Ellenzweig, A. (1997) 'Picturing the homoerotic', in Queer Representations: Reading Lives, Reading Cultures, ed. M. Duberman, New York University Press, New York and London, pp. 57-68.

Foucault, M. (1977) Discipline and Punish: the Birth of the Prison, Penguin, London.

Foucault, M. (1985) The Uses of Pleasure: History of Sexuality, Volume 2, Penguin, London.

Fraser, M. (1999) 'Classing queer: politics in competition', Theory, Culture \& Society, Vol. 16, no. 2, pp. 107-131.

Grosz, E. (1994) Volatile Bodies: Toward a Corporeal Feminism, Allen \& Unwin, St Leonards, NSW.

Grosz, E. (1995) Space, Time and Perversion: the Politics of Bodies, Routledge, London and New York.

Harvey, K. \& Shalom, C. (eds) (1997) Language and Desire: Encoding Sex, Romance and Intimacy, Routledge, London and New York.

Irigaray, L. (1985) This Sex Which is Not One, trans. C. Porter with C. Burke, Cornell University Press, Ithaca, NY.

Lacan, J. (1977) Écrits: a Selection, trans. Alan Sheridan, Tavistock/Routledge, London.

Lingis, A. (1994) Foreign Bodies, Routledge, London and New York.

Miller, N. (1995) Out of the Past: Gay and Lesbian History from 1869 to the Present, Vintage, London.

Mohr, R. (1992) Gay Ideas: Outing and Other Controversies, Beacon Press, Boston.

Mouffe, C. (1995) 'Democratic politics and the question of identity', in The Identity in Question, ed. J. Rajchman, Routledge, London and New York, pp. 33-45.

Patton, C. (1993) 'Embodying subaltern memory: kinesthesia \& the problematics of gender \& race', in The Madonna Connection: Representational Politics, Subaltern Identities, and Cultural Theory, ed. C. Schwichtenberg, Allen \& Unwin, St Leonards, NSW, pp. 81-105.

Pristel, S. (1999) 'Ad depicts Angus as a Gay Blade', Herald Sun, 30 Mar., p. 7.

Reed, D. (1999) 'Falwell calls “Teletubby” gay', Associated Press, 9 Feb., distributed by GLB-News Listserv: glb-news@listserv.aol.com

Rosello, M. (1998) Declining the Stereotype: Ethnicity and Representation in French Cultures, University Press of New England, Hanover, NH. 
Schulman, S. (1995) 'Gay identity and the media blitz', Lambda Book Report, Vol. 4, no. 8, pp. 12-14.

Sedgwick, E. K. (1990) Epistemology of the Closet, Penguin, London.

Sinfield, A. (1994) The Wilde Century: Effeminacy, Oscar Wilde and the Queer Movement, Columbia University Press, New York.

Whisman, V. (1996) Queer by Choice: Lesbians, Gay Men and the Politics of Identity, Routledge, London and New York.

Young, I. M. (1990) Throwing Like a Girl and Other Essays in Feminist Philosophy and Social Theory, Indiana University Press, Bloomington. 


\section{Author Query Sheet}

\begin{tabular}{|l|l|}
\hline \multicolumn{2}{|c|}{ Manuscript Information } \\
\hline Journal acronym & cCON \\
\hline $\begin{array}{l}\text { Volume and } \\
\text { issue }\end{array}$ & $18: 1$ \\
\hline Author name & Cover \\
\hline $\begin{array}{l}\text { Manuscript No. } \\
\text { (if applicable) }\end{array}$ & \\
\hline
\end{tabular}

\section{QUERY NO.}

QUERY DETAILS

AQ1 The sentence commencing "Tinky Winky is identified ..." seems to be incomplete in that there is no completion of the argument following "yet the grooming ..." Please advise. 